Jurnal

Manajemen Kesehatan Indonesia

Volume 5

Nomor 3

Desember 2017

\title{
Pengaruh Quality Of Work Life terhadap Keterlibatan Kerja Karyawan
}

Farouk Ilmid Davik*, Ernawaty**, Nyoman Anita Damayanti**

* Master student of Administration and Health Policy, Universitas Airlangga

**Lecturer Faculty of Public Health, Universitas Airlangga

Email:davik.fkmua@gmail.com 


\section{ABSTRACT}

Quality of Work Life (QWL) is the perception of security, satisfaction and perceived ability to develop employees to do the job. Quality of Work Life (QWL) can affect employee's job involvement. In March 2017, Undaan Surabaya Eye Hospital has a low category of employee's job involvement by $65,46 \%$. This study aims to analyze the influence of Quality of Work Life (QWL) to the involvement of employees in Undaan Eye Hospital Surabaya. This research was an observational study with cross sectional design. Data collection was carried out by handing out two kinds of questionnaires. The sample in this research were 62 permanent employees which based on the results of the calculation using simple random sampling formula. The influence of QWL towards employee's job involvement is analyzed using the univariate logistic regression test. Quality of Work Life (QWL) in Undaan Eye Hospital Surabaya was in medium category by $58.1 \%$. The level of employee engagement was in medium category by $88.7 \%$. The result showed that there was influence of the QWL towards the employee's job involvement with the significance of 0.000456. The result of $Q W L$ components and its influences toward employee engagement were supervision (sig=0,0002), allowances (sig=0,000002), and work design (sig = 0,00) (sig=0,000002). Allowance had the strongest influences toward employee's job involvement. In the meantime, working conditions didn't have any influence on employee's job involvement. QWL gave effect to work engagement. Efforts should be made to increase the involvement of employees is the management of Undaan Eye Hospital Surabaya more attention to the supervision of employees, benefits are balanced, clear job design, provided rewards for employees who perform well and sanctions for employees who was underperforming.
Keywords: job involvement, supervision, quality of work life, work design, working conditions

\section{PENDAHULUAN}

Salah satu upaya meningkatkan kemampuan sumberdaya manusia adalah menciptakan quality of work life (QWL) yang baik untuk memotivasi karyawan dalam bekerja. Menurut Cascio (2006) quality of work life adalah persepsi karyawan tentang keamanan dalam pekerjaan, kepuasan, keseimbangan antara kehidupan dan pekerjaan serta kemampuan untuk tumbuh dan berkembang sebagai manusia. Quality of work life merupakan masalah utama yang perlu mendapat perhatian organisasi (Lewis et al, 2001). Quality of work life memiliki hubungan dengan sikap kerja karyawan. Kualitas kehidupan kerja dipandang mampu meningkatkan peran serta karyawan terhadap organisasi. Chandramohan (2008) menyebutkan bahwa quality of work life mempengaruhi keterlibatan kerja.

Keterlibatan kerja adalah ukuran seorang karyawan secara psikologis terhadap pekerjaanya dan memandang bahwa kinerja yang dilakukan sebagai ukuran harga diri (Robbins, 2008). Keterlibatan kerja yang tinggi dapat memberikan pengaruh kuat terhadap organisasi dan hal tersebut dapat berpengaruh pula pada keberhasilan organisasi dalam mencapai tujuan (Rotenbarry \& Moberg, 2007). Keterlibatan kerja karyawan bagi organisasi dengan meningaktkan kinerja karyawan didalamnya. Quality of work life merupakan masalah utama yang perlu diperhatikan di dalam organisasi karena terkait dengan keberhasilan tujuan organisasi (Lewis, et al, 2001). Quality of work life dipengaruhi oleh beberapa faktor yaitu pengawasan, tunjangan, kondisi kerja, dan desain kerja (werther \& davis, 2002). Keempat komponen tersebut harus dapat dipenuhi oleh organisasi untuk menciptakan quality of work life yang baik.

Rumah Sakit Mata Undaan Surabaya merupakan Rumah Sakit tipe B yang telah terakreditasi paripurna oleh Komite 
Akreditasi Rumah Sakit (KARS). Rumah Sakit Mata Undaan Surabaya telah berupaya untuk melaksanakan pengelolaan sumberdaya manusia. Namun, terdapat hal yang belum dilaksanakan adalah pengukuran tingkat keterlibatan kerja karyawan di dalamnya. Keterlibatan kerja karyawan di Rumah Sakit Mata Undaan Surabaya pada bulan Maret 2017 adalah sebesar 65,28\%. Menurut teori Pareto terdapat aturan 80/20 yang berarti $80 \%$ masalah muncul karena $20 \%$ penyebab (Chinchuluun et al, 2008). Dengan demikian dapat disebutkan bahwa tingkat keterlibatan kerja karyawan di Rumah Sakit Mata Undaan Surabaya termasuk kategori rendah sebesar 65,465 pada Maret 2017.
Tujuan penelitian ini untuk menguji pengaruh quality of work life terhadap keterlibatan kerja karyawan. Hasil dari penelitian ini diharapkan dapat menjadi rekomendasi bagi Rumah Sakit untuk meningkatan quality of work life dan keterlibatan kerja karyawan.

\section{METODE PENELITIAN}

Jenis penelitian ini adalah penelitian observasional analitik dengan desain study cross sectional. Populasi dalam penelitian ini adalah karyawan tetap Rumah Sakit Mata Undaan Surabaya sebanyak 172 orang. Hasil perhitungan dengan rumus simple random sampling diperoleh sampel penelitian sejumlah 62 karyawan tetap.

Penelitian dilaksanakan pada bulan Desember 2016-Juni 2017 di Rumah Sakit Mata Undaan Surabaya. Teknik pengumulan data menggunakan instrument berupa kuesioner. Kuesioner telah dilakukan uji validitas dan uji reabillitas pada 20 karyawan. Hasil uji validitas terhadap 21 pertanyaan menunjukkan $r$ hitung $>r$ kritis $(0,444)$ berarti ahwa pertanyaan tersebut valid dan hasil uji reliabilitas pada setiap variabel bernilai koefisian Alpha Cronbach's > 0,60 sehingga dapat dinyatakan bahwa kuesioner penelitian ini berisi pertanyaan yang reliable.

Variabel independent dalam penelitian ini adalah quality of work life dengan empat indikator yang meliputi pengawasan, kondisi kerja, tunjangan, dan desain kerja. Variabel dependent adalah keterlibatan kerja karyawan yang terdiri dari dukungan kerja, partisipasi dalam pengambilan keputusan, dan ketergantungan tugas.

Langkah awal penelitian ini adalah mengukur quality of work life dan mengukur keterlibatan kerja karyawan secara bersamaan. Selanjutnya melakukan analisis pengaruh variabel independent terhadap variabel dependent dengan menggunakan uji regresi logistik univariat. Analisis data dilakukan setiap variabel dengan menggunakan skala likert

\section{HASIL DAN PEMBAHASAN \\ Karakteristik Karyawan di Rumah Sakit Mata Undaan Surabaya Berdasarkan Umur, Masa Kerja, dan Tingkat Pendidikan}

Berdasarkan tabel 1. mayoritas karyawan Rumah Sakit Mata Undaan Surabaya berusia kurang dari 30 tahun sebesar 56,4\% dengan masa kerja responden menjawab bekerja kurang dari 5 tahun sebesar 50\%. Tingkat pendidikan mayoritas responden adalah berpendidikan SMA sekitar 33,9\%.

Tabel 1. Karakteristik karyawan di RSM Undaan Surabaya Tahun 2017 
Hasil Pengukuran Quality of Wok Life Karyawan di Rumah Sakit Mata Undaan Surabaya

Pengukuran Quality of Work Life (QWL) dilakukan dengan menggunakan kuesioner yang terdapat 21 pernyataan. Penilaian variabel

Hasil Pengukuran Quality of Wok Life Karyawan di Rumah Sakit Mata Undaan Surabaya

Tabel 2. Kategori Quality of Work Life Karyawan Rumah Sakit Mata Undaan Surabaya Tahun 2017

\begin{tabular}{|c|c|c|}
\hline $\begin{array}{c}\text { Kategori } \\
\text { Penilaian } \\
\text { QWL }\end{array}$ & F & \% \\
\hline Rendah & 0 & 0 \\
\hline Cukup & 36 & 58,1 \\
\hline Tinggi & 26 & 41,9 \\
\hline Total & 62 & 100 \\
\hline
\end{tabular}

Mayoritas responden menilai tingkat Quality of Work Life (QWL) dalam kategori cukup yaitu sebesar 58,1\%. Berdasarkan perolehan persentase yang tersaji pada Tabel 5.6 dapat disimpulkan bahwa tingkat Quality of Work Life (QWL) di Rumah Sakit Mata Undaan Surabaya termasuk dalam kategori cukup

Tabel 3. Hasil pengukuran Persepsi Terhadap Komponen Quality of Work Life

\begin{tabular}{|c|l|c|c|}
\hline \multirow{2}{*}{ No. } & \multirow{2}{*}{ Dimensi } & \multicolumn{2}{|c|}{ Mean } \\
\cline { 3 - 4 } & & $\begin{array}{c}\text { Penilaia } \\
\text { n }\end{array}$ & $\mathbf{( \% )}$ \\
\hline 1. & Pengawasan & Cukup & $71 \%$ \\
\hline 2. & Kondisi Kerja & Cukup & 62,9 \\
\hline 3. & Tunjangan & Cukup & $85,5 \%$ \\
\hline 4. & Desain Kerja & Cukup & $85,5 \%$ \\
\hline
\end{tabular}

Berdasarkan tabel 3. Menjelaskan bahwa mayoritas karyawan RS Mata Undaan Surabaya merasa cukup terhadap komponen quality of work life yang meliputi pengawasan, kondisi kerja, tunjangan dan desain kerja.

Hasil Pengukuran Keterlibatan kerja Karyawan RS Mata Undaan Surabaya

Tabel 4. Hasil pengukuran keterlibatan kerja karyawan di RS Mata Undaan Surabaya Tahun 2017

\begin{tabular}{lcc}
\hline $\begin{array}{c}\text { Karakteristik } \\
\text { Karyawan }\end{array}$ & (f) & (\%) \\
\hline Usia (tahun) & & \\
\hline$<30$ & 35 & 56,4 \\
$31-40$ & 15 & 24,2 \\
$41-50$ & 6 & 9,7 \\
$>50$ & 6 & 9,7 \\
\hline Masa Kerja (tahun) & & \\
\hline$<5$ & 31 & 50 \\
$6-10$ & 13 & 21 \\
$11-15$ & 3 & 4,8 \\
$>15$ & 15 & 24,2 \\
\hline Tingkat Pendidikan & & \\
\hline SMA & 21 & 33,9 \\
D1/D3 & 20 & 32,2 \\
S1 & 19 & 30,6 \\
S2 & 2 & 3,2 \\
\hline
\end{tabular}




\begin{tabular}{|l|c|c|}
\hline \multicolumn{1}{|c|}{$\begin{array}{c}\text { Kategori } \\
\text { Penilaian }\end{array}$} & F & \% \\
\hline Rendah & 0 & 0 \\
\hline Cukup & 55 & 88,7 \\
\hline Tinggi & 7 & 11,3 \\
\hline Total & 62 & 100 \\
\hline
\end{tabular}

Dari tabel 4. Menjelaskan bahwa sebanyak 55 karyawan atau 88,7\% memiliki tingkat keterlibatan kerja kategori cukup. Karyawan yang memiliki tingkat keterlibatan kerja tinggi sebanyak tujuh orang dari 62 orang. Penilaian variabel keterlibatan kerja diukur secara menyeluruh berdasarkan 3 indikator antara lain dukungan dari kelompok kerja, partisipasi karyawan dalam pengambilan keputusan, dan ketergantungan tugas. Dari hasil pengukuran tersebut, tingkat keterlibatan kerja karyawan di Rumah Sakit Mata Undaan Surabaya sebesar $88,7 \%$ termasuk dalam kategori cukup.

Tabel 5. Hasil pengukuran Persepsi Terhadap Komponen Keterlibatan Kerja Karyawan

\begin{tabular}{|c|l|c|c|}
\hline \multirow{2}{*}{ No. } & \multicolumn{2}{|c|}{ Dimensi } & \multicolumn{2}{|c|}{ Mean } \\
\cline { 3 - 4 } & & Penilaian & $\mathbf{( \% )}$ \\
\hline 1. & Dukungan dari kelompok kerja & Cukup & $90,3 \%$ \\
\hline 2. & Partisipasi pengambilan keputusan & Cukup & $85,5 \%$ \\
\hline 3. & Ketergantungan tugas & Cukup & $90,3 \%$ \\
\hline
\end{tabular}

Berdasarkan tabel 5 . Menjelaskan bahwa mayoritas karyawan RS Mata Undaan Surabaya merasa cukup terhadap komponen keterlibatan kerja yang meliputi

5. dukungan kelompok kerja, partisipasi pengambilan keputusan dan ketergantungan tugas karyawan di Rumah Sakit Mata Undaan Surabaya.

Pengaruh Quality of Work Life terhadap Keterlibatan Kerja Karyawan

Tabel 6. Pengaruh Quality of Work life Terhadap Keterlibatan Karyawan Karyawan di Rumah

Sakit Mata Undaan Surabaya Tahun 2017

\begin{tabular}{|l|c|c|c|}
\hline $\begin{array}{l}\text { Quality of } \\
\text { Work Life }\end{array}$ & Jumlah & & \\
& Dimensi & & \\
Mean & & & \\
& Penilaian & & \\
$(\%)$ & & & \\
1. & & \\
& $\begin{array}{l}\text { Exp (B) } \\
\text { Pengawasan } \\
\text { Cukup } \\
71 \%\end{array}$ & & \\
\hline
\end{tabular}




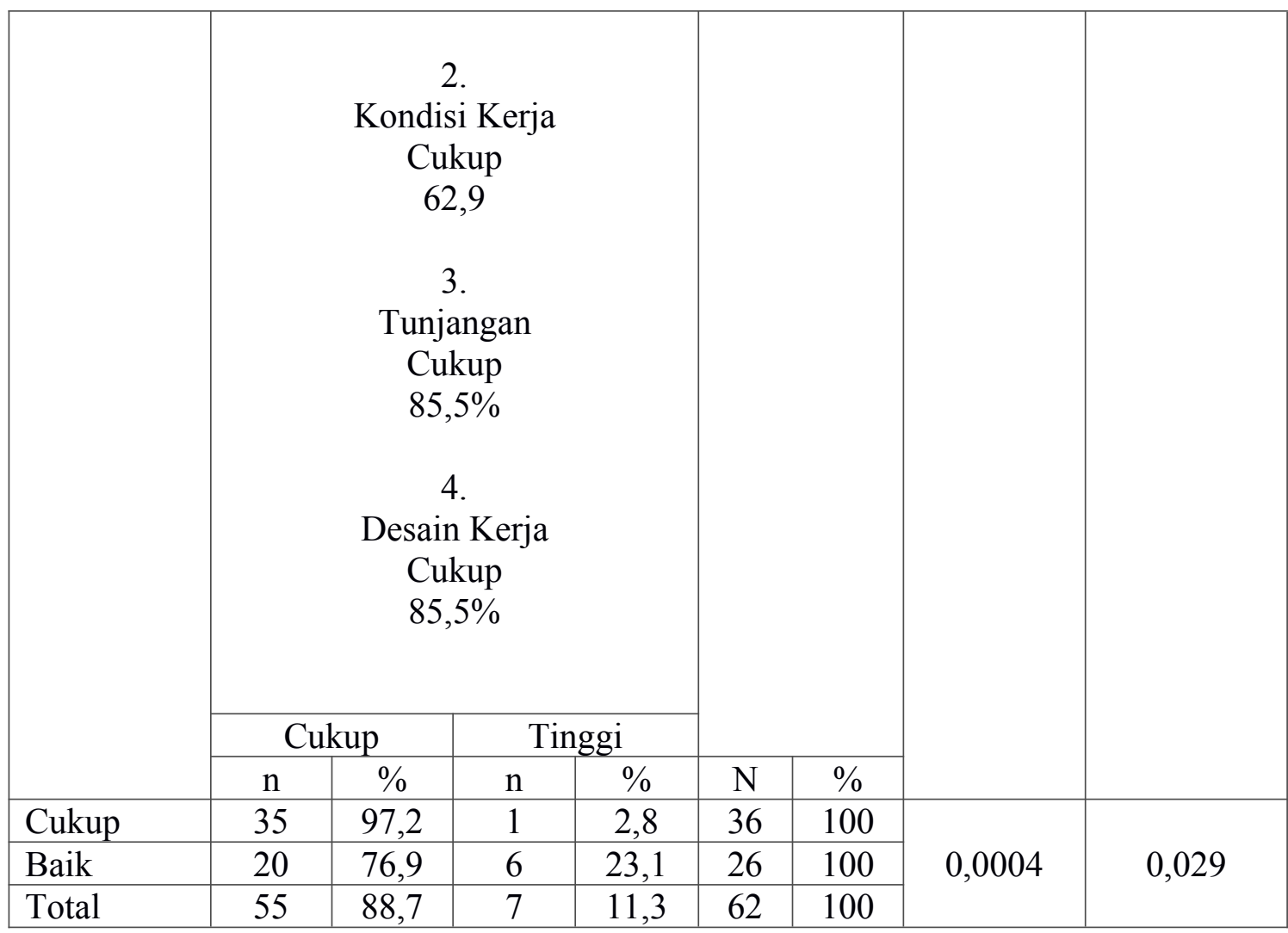

Berdasarkan tabel 6. dapat diketahui bahwa responden yang menilai Quality of Work Life dalam kategori cukup dengan keterlibatan kerja tinggi diperoleh hasil sebesar $2,8 \%$. Quality of Work Life yang dinilai responden dalam kategori baik dengan keterlibatan kerja tinggi diperoleh hasil sebesar 23,1\%. Berdasarkan hasil tersebut maka dapat disimpulkan semakin baik Quality of Work Life maka tingkat keterlibatan kerja karyawan semakin tinggi.

Uji pengaruh Quality of Work Life (QWL) terhadap keterlibatan kerja karyawan dilakukan menggunakan uji regresi logistik univariat. Uji pengaruh dilakukan secara menyeluruh dan parsial dari komponen Quality of Work Life (QWL). Uji pengaruh parsial yang dimaksud adalah tiap komponen pada Quality of Work Life (QWL) terdiri atas pengawasan, kondisi kerja, tunjangan, dan desain kerja yang masing-masing dilakukan uji pengaruh terhadap keterlibatan kerja. Berdasarkan uji pengaruh diperoleh hasil signifikansi atau $p$-value sebesar $0,0004<0,05$ yang berarti terdapat pengaruh Quality of Work Life (QWL) terhadap keterlibatan kerja karyawan dengan nilai Exp. (B) sebesar 0,029, bahwa kemungkinan karyawan yang menilai Quality of Work Life (QWL) termasuk dalam kategori tinggi akan memiliki keterlibatan kerja yang tinggi sebesar 34,48 $(1 / 0,029) \mathrm{kali}$ lebih besar daripada karyawan yang menilai Quality of Work Life (QWL) dalam kategori cukup. Sehingga, Quality of Work Life (QWL) yang tinggi memiliki kecenderungan menciptakan keterlibatan kerja karyawan yang tinggi pada instansi. 
Tabel 7. Hasil Uji Pengaruh Komponen Quality of Work Life Terhadap Keterlibatan Kerja

Karyawan di Rumah Sakit Mata Undaan Surabaya Tahun 2017

\begin{tabular}{|c|c|c|c|c|c|c|c|c|c|}
\hline \multirow{3}{*}{\multicolumn{2}{|c|}{ Variabel QWL }} & \multicolumn{4}{|c|}{ Keterlibatan Kerja } & \multirow{2}{*}{\multicolumn{2}{|c|}{ Jumlah }} & \multirow{3}{*}{ P-value } & \multirow{3}{*}{$\begin{array}{l}\text { Exp } \\
\text { (B) }\end{array}$} \\
\hline & & \multicolumn{2}{|c|}{ Cukup } & \multicolumn{2}{|c|}{ Tinggi } & & & & \\
\hline & & $\mathbf{N}$ & $\%$ & $\mathbf{n}$ & $\%$ & $\mathbf{n}$ & $\%$ & & \\
\hline \multirow{2}{*}{ Pengawasan } & Cukup & 43 & 97,7 & 1 & 2,3 & 44 & 100 & \multirow{2}{*}{0,0002} & \multirow{2}{*}{0,23} \\
\hline & Tinggi & 12 & 66,7 & 6 & 33,3 & 18 & 100 & & \\
\hline \multirow{2}{*}{$\begin{array}{l}\text { Kondisi } \\
\text { Kerja }\end{array}$} & Cukup & 39 & 100 & 0 & 0 & 39 & 100 & \multirow{2}{*}{0,9973} & \multirow{2}{*}{0,00} \\
\hline & Tinggi & 16 & 69,6 & 7 & 30,4 & 23 & 100 & & \\
\hline \multirow{2}{*}{ Tunjangan } & Cukup & 50 & 90,3 & 3 & 5,7 & 53 & 100 & \multirow{2}{*}{0,0000} & \multirow{2}{*}{0,60} \\
\hline & Tinggi & 5 & 55,6 & 7 & 44,4 & 9 & 100 & & \\
\hline \multirow{2}{*}{$\begin{array}{c}\text { Desain } \\
\text { kerja }\end{array}$} & Cukup & 51 & 96,2 & 2 & 3,8 & 53 & 100 & \multirow{2}{*}{0,0007} & \multirow{2}{*}{0,03} \\
\hline & Tinggi & 4 & 44,4 & 5 & 55,6 & 9 & 100 & & \\
\hline
\end{tabular}


Berdasarkan Tabel 7. diperoleh hasil bahwa terdapat tiga komponen yang memiliki signifikansi atau p-value kurang dari $\alpha(0,05)$ antara lain pengawasan, tunjangan, dan desain kerja. Kondisi kerja tidak memiliki pengaruh dengan keterlibatan kerja karena p-value sebesar $0,997>0,05$.

Terdapat pengaruh antara pengawasan terhadap keterlibatan kerja karyawan dengan p-value sebesar 0,00 yang lebih kecil dari $\alpha(0,05)$. Dengan nilai Exp. (B) sebesar 0,023. Artinya, kemungkinan karyawan yang menilai tentang pengawasan termasuk dalam kategori tinggi akan memiliki keterlibatan kerja yang tinggi pula sebesar 43,48 $(1 / 0,023)$ kali lebih besar daripada dengan karyawan yang menilai pengawasan dalam kategori cukup. Berdasarkan perolehan hasil uji pengaruh pengawasan terhadap keterlibatan kerja karyawan dapat diketahui bahwa pengawasan yang tinggi memiliki kecenderungan menciptakan keterlibatan kerja karyawan yang tinggi pada instansi.

Komponen tunjangan memiliki pengaruh terhadap keterlibatan kerja karyawan dengan p-value $0,000<0,05$. Karyawan yang menilai tentang tunjangan termasuk dalam kategori tinggi akan memiliki keterlibatan kerja yang tinggi sebesar 16,67 (1/0,060) kali lebih besar daripada karyawan yang menilai tunjangan dalam kategori cukup. Sehingga, tunjangan karyawan yang tinggi memiliki kecenderungan menciptakan keterlibatan kerja karyawan yang tinggi pada instansi.

Terdapat pengaruh antara desain kerja terhadap keterlibatan kerja karyawan. Nilai Exp. (B) yang diperoleh pada uji pengaruh desain kerja terhadap keterlibatan kerja sebesar 0,039. Nilai Exp.

(B) sebesar 0,039 berarti bahwa kemungkinan karyawan yang menilai tentang desain kerja termasuk dalam kategori tinggi akan memiliki keterlibatan kerja yang tinggi sebesar $25,64(1 / 0,039)$ kali lebih besar daripada karyawan yang menilai desain kerja termasuk dalam kategori cukup. Berdasarkan perolehan hasil uji pengaruh desain kerja terhadap keterlibatan kerja karyawan dapat dilihat bahwa desain kerja yang tinggi memiliki kecenderungan menciptakan keterlibatan kerja karyawan yang tinggi pada instansi. komponen Quality of Work Life (QWL) yang memiliki signifikansi $<\alpha$ dengan angka paling kecil adalah komponen tunjangan. Siginifikan pada uji pengaruh komponen tunjangan terhadap keterlibatan kerja sebesar 0,000. Uji pengaruh dengan signifikan paling kecil berarti memiliki pengaruh paling kuat. Sehingga tunjangan memiliki pengaruh paling kuat terhadap keterlibatan kerja karyawan daripada komponen yang lain.

\section{PEMBAHASAN}

\section{Pengaruh Quality of Work Life Terhadap Keterlibatan Kerja Karyawan}

Quality of Work Life menurut Flippo (2005) adalah setiap aktivitas perbaikan di setiap tingkatan dalam suatu organisasi yang bertujuan untuk meningkatkan efektivitas organisasi melalui peningkatan martabat dan pertumbuhan karyawan. Quality of work life sebagai pendekatan yang mencakup adanya banyak kegiatan yang beragam di tempat kerja agar memajukan pertumbuhan dan martabat karyawan, bekerja sama, saling membantu, menentukan perubahan kerja secara partisipatif, dan menganggap tujuan karyawan dan organisasi dilaksanakan bersama.

Hasil analisis uji regresi univariat menunjukkan bahwa terdapat pengaruh Quality of Work Life terhadap keterlibatan kerja karyawan di Rumah Sakit Mata Undaan Surabaya dengan nilai p-value $0,0004<0,05$. Nilai Exp. (B) yang diperoleh sebesar 0,029 menunjukkan bahwa kemungkinan karyawan yang menilai Quality of Work Life (QWL) termasuk dalam kategori tinggi akan memiliki keterlibatan kerja yang tinggi sebesar 34,48 kali lebih besar daripada karyawan yang menilai Quality of Work 
Life (QWL) termasuk dalam kategori cukup.

Hasil penelitian ini mendukung hasil penelitian yang dilakukan oleh Mehdipour (2012), menyebutkan bahwa terdapat hubungan yang positif antara Quality of Work Life (QWL) dan keterlibatan kerja. Tunjangan merupakan komponen dari Quality of Work Life yang memiliki pengaruh paling kuat terhadap keterlibatan kerja karyawan. Kemungkinan karyawan yang menilai komponen tunjangan termasuk dalam kategori tinggi akan memiliki keterlibatan kerja yang tinggi sebesar 16,67 kali lebih besar daripada karyawan yang menilai tunjangan dalam kategori cukup.

Cascio (2003) menyatakan bahwa tujuan adanya sistem kompensasi yaitu menarik, menahan, dan memotivasi karyawan untuk mencapai keadilan antara karyawan dan organisasi atau instansi. Upaya pemberian tunjangan yang dilaksanakan di Rumah Sakit Mata Undaan Surabaya terbukti dengan hasil penelitian bahwa dapat memotivasi karyawan dan menjadikan karyawan lebih loyal terhadap organisasi. Dengan demikian dapat memberikan keuntungan bagi Rumah Sakit Mata Undaan karena dapat menjadikan keterlibatan kerja karyawan semakin meningkat.

\section{Pengaruh Komponen Quality of Work Life Terhadap Keterlibatan Kerja Karyawan}

\section{Pengawasan}

Rabinowitz dan Hall (1977) menjelaskan bahwa terdapat hubungan antara pengawasan dengan keterlibatan kerja. Nilai Exp. (B) yang diperoleh sebesar 0,023 yang berarti kemungkinan karyawan yang menilai pengawasan termasuk dalam kategori tinggi akan memiliki keterlibatan kerja yang tinggi pula sebesar 43,48 kali lebih besar daripada dengan karyawan yang menilai pengawasan dalam kategori cukup.

Berpengaruhnya pengawasan terhadap keterlibatan kerja menjelaskan bahwa pihak manajemen sebagai pengawas telah menjalankan perannya dengan cukup baik. Peran tersebut mencakup kemampuan yang dimiliki oleh pengawas yaitu menempatkan karyawan secara tepat sesuai dengan pekerjaan, berkomunikasi yang baik dengan karyawan, dan mampu mengarahkan karyawan dalam melaksanakan tugas dengan baik. Pengawas yang memenuhi kemampuan tersebut terbukti dapat memberikan dampak positif terhadap keterlibatan kerja karyawan.

\section{Tunjangan}

Menurut Mondy dan Noe (2005) menyebutkan bahwa tunjangan merupakan kompensasi finansial tidak langsung seperti jaminan sosial, uang pesangon, jaminan kesehatan, pensiun, dan sebagainya. Rumah Sakit Mata Undaan telah menerapkan sistem pemberian tunjangan untuk memenuhi kebutuhan fisik karyawan.

Berdasarkan hasil penelitian dapat diketahui bahwa sebagian besar karyawan memberikan penilaian pada komponen tunjangan di Rumah Sakit Mata Undaan Surabaya sebesar $85,5 \%$ dalam kategori cukup. Perolehan kategori cukup berdasarkan penilaian karyawan terhadap tunjangan yang dirasakan selama bekerja di Rumah Sakit Mata Undaan Surabaya.

Penilaian karyawan terhadap tunjangan terdiri atas pernyataan besar tunjangan yang diterima karyawan adil sesuai dengan pekerjaan, tunjangan yang diberikan dapat menyejahterakan kehidupan karyawan, tunjangan kesehatan dapat memberikan rasa aman bagi karyawan, tunjangan yang diberikan dapat memotivasi karyawan, dan pemberian tunjangan menjadikan karyawan lebih loyal terhadap organisasi.

Berdasarkan teori Pareto menjelaskan berarti hasil penilaian responden terhadap pernyataan pada pengukuran tunjangan yang kurang dari $80 \%$ perlu mendapat perhatian oleh pihak manajemen Rumah Sakit Mata Undaan Surabaya. 
Menurut Purnawanto struktur penggajian ditentukan berdasarkan keterampilan atau kompetensi karyawan terdapat dua sifat yaitu adil secara internal, kompetitif apabila dibandingkan dengan lingkungan eksternal, dan efisien untuk dikelola. Adil secara internal yang dimaksud adalah karyawan yang memiliki jabatan lebih tinggi akan memperoleh gaji yang lebih besar daripada rekan kerja yang memiliki jabatan lebih rendah. Adil secara merata berarti bahwa tinggi rendah jabatan ditentukan oleh kemampuan dan keterampilan yang dimiliki.

Berkaitan dengan hal tersebut, pihak manajemen dapat melakukan evaluasi terhadap tunjangan yang diterapkan di Rumah Sakit Mata Undaan Surabaya dengan memperhatikan pada pernyataan besar tunjangan yang diterima oleh karyawan adil sesuai dengan pekerjaan yang telah dilakukan, tunjangan yang diberikan dapat menyejahterakan kehidupan karyawan, dan besar tunjangan kesehatan yang diberikan memberikan rasa aman bagi karyawan.

\section{Desain Kerja}

Sebagian besar responden memberikan penilaian pada desain kerja di Rumah Sakit Mata Undaan Surabaya sebesar 85,5\% dalam kategori cukup. Perolehan kategori cukup berdasarkan penilaian responden terhadap desain kerja yang dirasakan saat bekerja di Rumah Sakit Mata Undaan Surabaya.

Indikator yang digunakan untuk menilai desain kerja antara lain karyawan memiliki pemahaman terhadap uraian pekerjaan yang ditetapkan, kemudahan karyawan dalam menyelesaikan pekerjaan, karyawan memiliki kemampuan dalam menyelesaikan pekerjaan, karyawan mendapatkan umpan balik berupa informasi terkait kinerja yang telah dilakukan, dan karyawan memiliki keleluasaan dan kebijaksanaan yang dapat dipertanggungjawabkan dalam melaksanakan pekerjaan. Meskipun hasil penilaian komponen desain kerja dalam kategori cukup, masih terdapat persentase paling rendah yaitu pada pernyataan kemudahan karyawan dalam menyelesaikan pekerjaan adalah sebesar $77,4 \%$ dalam kategori setuju. Hal tersebut perlu diberikan perhatian oleh pihak manajemen Rumah Sakit Mata Undaan Surabaya.

Pihak manajemen Rumah Sakit Mata Undaan dapat mengevaluasi dan meningkatkan tingkat desain kerja dengan menggunakan pendekatan spesifikasi pemerkayaan pekerjaan agar menjadi lebih baik. Menurut Greenberg dan Baron (2001), berkaitan dengan pemerkaya pekerjaan terdapat spesifikasi antara lain:

a. Skill variety adalah menekankan karyawan pada keahlian yang dimiliki dan dibutuhkan dalam menyelesaikan pekerjaan.

b. Task identity adalah karyawan menyelesaikan pekerjaan secara bertahap mulai dari awal, proses hingga akhir.

c. Task significance adalah tingkat suatu pekerjaan memiliki pengaruh penting bagi kehidupan atau pekerjaan orang lain baik di dalam maupun di luar lingkungan organisasi.

d. Autonomy adalah karyawan memiliki keleluasaan dan kebijaksanaan yang dapat dipertanggungjawabkan untuk perencanaan, penjadwalan, dan pelaksanaan pekerjaan.

e. Feedback merupakan karyawan memperoleh umpan balik informasi terkait kinerjanya.

\section{KESIMPULAN}

Quality of work life berpengaruh terhadap keterlibatan kerja karyawan dengan nilai p-value $0,0004<0,05$. Semakin tinggi quality of work life maka semakin tinggi tingkat keterlibatan karyawan. Komponen quality of work life yang berpengaruh terhadap keterlibatan kerja adalah pengawasan, desain kerja dan tunjangan, sedangkan kondisi kerja tidak berpengaruh terhadap keterlibatan kerja.

Tunjangan memiliki nilai pengaruh paling kuat terhadap keterlibatan kerja karyawan. Peningkatan keterlibatan kerja dapat dilakukan dengan meningkatkan 
kemampuan pengawasan, tunjangan yang sesuai dengan kinerja, desain kerja yang jelas dan memberikan reward pada karyawan untuk meningkatkan quality of work life karyawan di Rumah Sakit Mata Undaan Surabaya.

\section{DAFTAR PUSTAKA}

Bernardin, H. J. and Russel, J.E.A., 1993. Humans Resource Management : an Experimental Approach. Singapore: McGraw Hill. Inc.

Brown, S. P. and Leigh, T. W., 1996. A New

Look At Psychological Climate and Its Relationship to Job Involvement, Effort, And Performance. Journal of Applied Psychology, 81(4):pp.358-368.

Cascio, W. F., 2006.Managing Human Resources: Productivity, Quality of Work Life, Profits. $7^{\text {th }}$ ed. New York:Mc Graw-Hill.

Chandramohan, 2008. Human Resource Management. New Delhi: APH Publishing Corporation.

Chinchuluun, A., Pardalos, P. M., Migdalas,

A. and Pitsoulis, L., 2008. Pareto Optimality, Game Theory And Equilibria. New York: Springer.

Danish, R.Q., Shahid, A. U., Aslam, N., Afzal, M., and Ali, H. Y., 2015. Relationship Between Job Performace, Job Involvement and Career Salience of Employees in Education Sector of Pakistan. American Journal of Educational Science, [e-journal] 1(2):pp.19-23. Tersedia di: $<$ www.aiscience.org/journal/ajes $>$ [diakses tanggal 26 Mei 2017].

Davis, K and Newstrom., 1995. Perilaku dalam Organisasi. Jakarta : Erlangga.

Flippo, E. B., 2005.Manajemen

Personalia.Edisi Keenam . Jakarta : Raja Grafindo.
Gautam, P.K., 2016. Gender Differences on

Employee Motivation and Job Involvement with Job Rotation Practices. [e-Jurnal] Vol 2 No 1. Tersedia di : $<$ https://nesfield.edu.np/attachments/ article/36/Prakash\%20Kumar\%20G autam $\% 20$ and $\% 20 \mathrm{Nitu} \% 20$ Adhika ri.pdf $>$ [diakses tanggal 8 Juni 2017]

Gibson, J. L. Ivancevich, J.M., and Donnelly,

H., 1994. Organisasi: Perilaku, Struktur dan Proses. Jakarta: Erlangga.

Greenberg, G. and Baron, R. A., 2001.Behaviour In Organization. 5th ed. New Jersey: Prentice Hall, Inc.

Hariandja, M.T.E., 2007. Manajemen Sumber Daya Manusia:Pengadaan, Pengembangan, kompensasi, dan Peningkatan Produktivitas Pegawai. Jakarta:Grasindo.

Khan, T. I., Jam, F.A., Akbar, A., and Hijazi,

S.T., 2011. Job Involvement as Predictor of Employee Commitment: Evidence from Pakistan. International Journal of Business and Management, 6(4):pp.252.

Kreitner, R. and Kinicki, A., 2004.

Organizational Behavior. 5th Ed. New Yor:McGraw Hill.

Leonard, E. C. and Hilgert, R. L., 2004.

Supervision, Concepts And Practices Management. $9^{\text {th }}$ edition. Ohio: Thomson Learning.

Lewis, D., Brazil, K., Krueger, P., Lohfeld, $\mathrm{L}$,

and Tjam, E., 2001. Extrinsic and Intrinsic Determinants of Quality of Work Life, 14(2): pp. ix-Xv.

Luthans, F., 2008. Organizational Behavior.

New York : McGraw Hill.

Mehdipour, A., Boushehri, S. N. S., Saemi, 
E., and Rayegan, A., 2012. Relationship Between The Quality of Working Life and Job Involvement of Iranian Physical Education Teachers. Studies in Physical Culture and Tourism, 19(4): pp. 185-190. Tersedia di: < http://rms.scu.ac.ir/Files/Articles/Jo urnals/Abstract/ST_2012_4_185.pd f2013225142419246.pdf $>$ [diakses tanggal 28 Mei 2017].

Mejia, L.R, Balkin, D.B, and Cardy, R.L., 2001.Managing Human Resources. New Jersey:Prentice Hall Inc.

Mondy, R.W and Noe, R.M., 2005. Human Resource Management.USA: Prentice Hall.

Moynihan, D.P. and Pandey, S.K., 2007.

Finding Workable Levers over Work Motivation: Comparing Job Satisfaction, Job Involvement and Organizational Commitment. Working Paper Series, [e-journal]. Tersedia di: < http://www.lafollette.wisc.edu/imag es/publications/workingpapers/moy nihan2007-003.pdf $>$ [diakses tanggal 30 Mei 2017].

Nawawi, H. H., 2005. Manajemen Sumber Daya Manusia untuk Bisnis yang Kompetitif. Yogyakarta: Gajah Mada University Press 